\title{
AVALIAÇÃO DA EFICIÊNCIA DO LAVADOR DE GASES DO TIPO VENTURI NO CONTROLE DAS EMISSÕES DE GASES E PARTICULADOS EMITIDOS NA COMBUSTÃO DE
} MARAVALHA DE PINUS

\author{
A. P. S. da SILVA ${ }^{1}$, M. A. M. $\operatorname{COSTA}^{1}$, J. E. F. CIESLINSKI ${ }^{1}$, J. A. de CARVALHO. Jr ${ }^{2}$, T. \\ GOMES $^{3}$, F. de ALMEIDA FILHO ${ }^{1}$, F. F. MARCONDES ${ }^{1}$. \\ ${ }^{1}$ Universidade Estadual Paulista "Júlio de Mesquita Filho" - UNESP, Departamento de Engenharia \\ Industrial Madeireira \\ ${ }^{2}$ Universidade Estadual Paulista, Departamento de Energia \\ ${ }^{3}$ INPE \\ E-mail para contato: ana.paula@grad.itapeva.unesp.br
}

\begin{abstract}
RESUMO - Emissões de gases e particulados provenientes da queima de biomassa vegetal danificam a qualidade do ar, afetam a saúde e o clima. Na queima de biomassa, gases tóxicos como $\mathrm{CO}, \mathrm{CO}_{2}, \mathrm{NO}_{\mathrm{X}}$ e particulados são emitidos. A maravalha de pinus é utilizada em grande escala nas indústrias que queimam biomassa vegetal. No controle da emissão de particulados e poluentes gasosos o lavador Venturi é um equipamento de coleta eficiente. O presente trabalho teve por objetivo avaliar a eficiência do lavador Venturi na coleta de gases e partículas menores que $2,5 \mu \mathrm{m}$ emitidos com a queima de biomassa. Realizou-se a queima experimental da maravalha de pinus e a amostragem dos poluentes em tempo real de queima, obtendo-se a eficiência na coleta de partículas e gases. Para as amostragens foram utilizados dois equipamentos: DataRam 4 monitor contínuo de partículas e o Eurotron, um monitor de gases. Os resultados de eficiência alcançados pelo lavador na coleta de gases da queima de maravalha de pinus foram: 96,14 $\%$ de $\mathrm{CO}, 92,12 \%$ de $\mathrm{CO}_{2}$ e 94,37\% de $\mathrm{NO}_{\mathrm{X}}$ na queima de maravalha de pinus.
\end{abstract}

\section{INTRODUÇÃO}

Um dos principais combustíveis utilizados pela indústria é a biomassa. Segundo Müller (2008) pode ser considerado biomassa todo recurso renovável que provêm de matéria orgânica de origem vegetal ou animal - tendo por objetivo principal a produção de energia. Existem diversas rotas para a produção de energia a partir de biomassa, com extensa variedade de fontes, que vão desde os resíduos agrícolas, industriais e urbanos até as culturas plantadas exclusivamente para a obtenção de biomassa. As tecnologias para os processos de conversão são as mais diversas possíveis e incluem desde a simples combustão ou queima para a obtenção da energia térmica até processos físico-químicos e bioquímicos complexos para a obtenção de 
combustíveis líquidos e gasosos.

Uma das principais vantagens da biomassa é que seu aproveitamento pode ser feito diretamente, por meio da combustão em fornos, caldeiras, etc. Para que seja aumentada a eficiência e sejam reduzidos os impactos socioambientais no processo de sua produção, porém, estão sendo desenvolvidas e aperfeiçoadas tecnologias de conversão mais eficientes como a gaseificação e a pirólise, também sendo comum a co-geração em sistemas que utilizam a biomassa como fonte energética. A combustão de biomassa é uma fonte de partículas finas (PM), monóxido de carbono ( $\mathrm{CO})$, óxidos de nitrogênio $\left(\mathrm{NO}_{\mathrm{X}}\right)$ e compostos orgânicos voláteis, incluindo componentes tóxicos e cancerígenos, tais como hidrocarbonetos aromáticos policíclicos (KISTLER et al., 2012). A poluição do ar tem mostrado ser um fator causador de doenças crônicas do aparelho respiratório, em vários graus de gravidade que vão desde pequenas alergias até severas lesões pulmonares.

Com o aumento do número de indústrias nos centros urbanos, cresce também a preocupação com o monitoramento e controle dos resíduos lançados à atmosfera, de modo a serem evitados danos ao meio ambiente e a saúde humana. Os resíduos liberados podem ser tanto gasosos quanto particulados. A primeira categoria é a que apresenta maior dificuldade de controle, devido à solubilidade dos agentes químicos no ar. De acordo com a Companhia Ambiental do Estado de São Paulo (CETESB) (2011), o material particulado pode ser classificado de acordo com seu diâmetro aerodinâmico em partículas totais em suspensão - PTS (com diâmetro aerodinâmico inferior a $50 \mu \mathrm{m}$ ) e partículas inaláveis - PI (com diâmetro aerodinâmico inferior a $10 \mu \mathrm{m}$ ). Estas últimas podem, ainda, ser divididas em partículas inaláveis grossas (com diâmetro aerodinâmico entre 2,5 e $10 \mu \mathrm{m}$ ) e partículas inaláveis finas (com diâmetro aerodinâmico inferior a 2,5 $\mu \mathrm{m}$ ). As partículas finas, devido ao seu tamanho diminuto, podem atingir os alvéolos pulmonares, já as grossas ficam retidas na parte superior do sistema respiratório. A faixa de tamanho de partículas $(5 \mu \mathrm{m}>\mathrm{d}>0,5 \mu \mathrm{m})$ são danosas ao sistema respiratório por seu poder de penetração e disposição nos aparelho respiratório. Os principais poluentes gasosos são $\mathrm{CO}, \mathrm{CO}_{2}$ e $\mathrm{NO}_{\mathrm{X}}$.

A indústria sempre enfrentou o problema de coletar poeiras muito finas e material particulado muito fino. Equipamentos de controle ambiental tais como precipitadores eletrostáticos e filtros de manga são inteiramente satisfatórios para muitas atividades com estas características. Os lavadores Venturi podem controlar simultaneamente poluentes particulados e gasosos, o que incentivou o uso deste lavador neste trabalho.

Segundo Ricco Junior (2007) lavadores Venturi são equipamentos muito apropriados, especialmente em aplicações onde a eficiência de coleta exigida seja superior a $90 \%$ para partículas de $1 \mu \mathrm{m}$ ou menores. Eles apresentam uma seção gradualmente convergente e uma seção divergente. O líquido de lavagem é injetado no interior do Venturi, normalmente na garganta, por diferentes formas. Utilizando geralmente água, mas podendo utilizar outros líquidos dependendo da natureza do contaminante.

Poumohammadbagher et al. (2011), realizaram um estudo sobre remoção simultânea de poluentes gasosos $\left(\mathrm{NO}, \mathrm{NO}_{2}, \mathrm{SO}_{2}\right.$ e $\left.\mathrm{CO}_{2}\right)$ com o auxílio de um lavador Venturi e tendo como 
líquidos a água e uma solução $2 \%$ v/v de $\mathrm{NaOH}$.

Mi e Yu (2012), assim como Gama (2008) e Tabari e Mohebbi (2008), estudaram a eficiência de um lavador Venturi na remoção de partículas poluentes. Os resultados obtidos por Mi e Yu (2012) demonstram que as máximas eficiências para as partículas com $10 \mu \mathrm{m}$ e $45 \mu \mathrm{m}$ foram, respectivamente, $92,7 \%\left(200 \mathrm{mg} / \mathrm{m}^{3}\right)$ e $95,1 \%\left(260 \mathrm{mg} / \mathrm{m}^{3}\right)$. Segundo os autores, há uma influência do tamanho (diâmetro) da partícula na eficiência de remoção.

As principais vantagens dos lavadores Venturi comparado com outros lavadores de gases e outros equipamentos de limpeza são: é um equipamento de estrutura compacta, ocupando um espaço menor na instalação industrial, os líquidos de lavagem podem ser reutilizados, os contaminantes particulados e gasosos podem ser removidos simultaneamente resultando economia de recursos. As desvantagens são: requerem alta energia para remoção de partículas finas, apresentam alto custo operacional, requerem o tratamento do efluente, dependendo do contaminante.

\section{OBJETIVOS}

Este trabalho teve como objetivo realizar a amostragem e o controle da emissão de material particulado e gasoso $\left(\mathrm{CO}, \mathrm{CO}_{2}\right.$ e $\left.\mathrm{NO}_{\mathrm{X}}\right)$ em tempo real na queima de maravalha de pinus (combustível industrial). Para tanto, foram utilizados dois equipamentos de amostragem e um de controle de emissão (lavador Venturi retangular).

\section{MATERIAIS E MÉTODOS}

\subsection{Equipamentos}

\section{Amostragem}

Eurotron (Ecoline 4000)

A amostragem de gases emitidos com a queima de maravalha de pinus foi realizada simultaneamente à amostragem de material particulado. $\mathrm{O}$ instrumento de amostragem foi $\mathrm{o}$ UniGas 3000+ da Eurotron Instruments. A amostragem de gases foi feita em dois pontos diferentes no módulo de queima, um antes e outro após o lavador Venturi. Para a amostragem foram utilizados dois Eurotrons que operaram simultaneamente.

\section{DR4000 (Dataram 4)}

$\mathrm{O}$ instrumento utilizado para a amostragem de material particulado em dutos (amostrador) foi o DataRAM4. Ele foi projetado para medir a concentração de matéria particulada (líquida ou sólida) em aspersão no ar, assim como o tamanho médio da partícula, a temperatura e umidade do fluxo gasoso, fornecendo leitura discreta e contínua, bem como o registro eletrônico dessas 
informações. A sonda do Dataram foi inserida em pontos antes e após o lavador Venturi, para apresentar os valores de concentração da partícula trocando de pontos de amostragem a medida da realização do experimento.

Queimador

A câmara de combustão (queimador de biomassa) possui um ventilador responsável por manter a chama acesa. Há um sistema de controle de vazão de ar para manutenção da qualidade da combustão (queima). Além destes, possui uma grelha interna que distribui o ar gerado pelo ventilador, um cinzeiro para recolhimento de resíduos e uma porta lateral para manutenções. Este conjunto condiciona uma chama com temperatura entre 800 e $1200^{\circ} \mathrm{C}$.

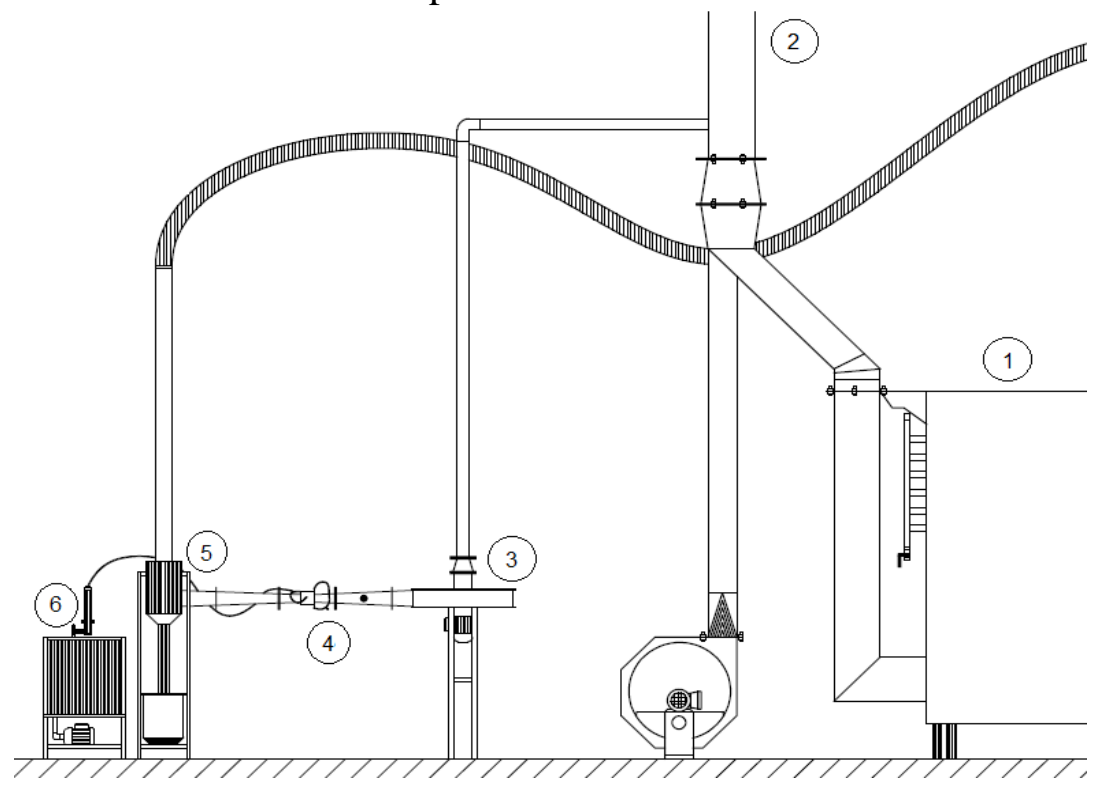

Figura 1 - Módulo experimental de controle de material particulado e gases.

Onde:

1 = gases provenientes da combustão

2 = chaminé com gases e partículas confinadas provenientes da combustão da biomassa

3 = soprador de ar para coleta de gases e partículas

4 = lavador Venturi

$5=$ ciclone separador de gotas

6 = sistema de alimentação de água.

\section{Controle de emissão}

Lavador Venturi

O lavador Venturi retangular utilizado na coleta de gases e partículas foi operado com quatro pontos de injeção de líquido, uma na garganta com $117 \mathrm{~mm}$ de comprimento e vazões de líquido de 0,4 a $1 \mathrm{~L} / \mathrm{min}$. O líquido de lavagem foi a água. 


\section{Resultados e Discussões}

\subsection{Remoção de particulados}

Na figura 2 são mostrados os valores da concentração média para cada vazão de material particulado em $\mu \mathrm{g} / \mathrm{m}^{3}$ iniciando sem a vazão de líquido para o interior do lavador Venturi e depois com as diferentes vazões de água utilizadas: 0,4, 0,6, 0,8 e $1 \mathrm{~L} / \mathrm{min}$. Pode-se observar que com o aumento da vazão de água ocorreu a diminuição da concentração de material particulado nos gases de exaustão do queimador. De forma a comprovar a eficiência do Lavador Venturi, na figura 3 são apresentados os valores calculados de eficiência para o equipamento. Foi observado que o aumento da vazão de água aumentou a eficiência do processo, reduzindo a concentração de material particulado.

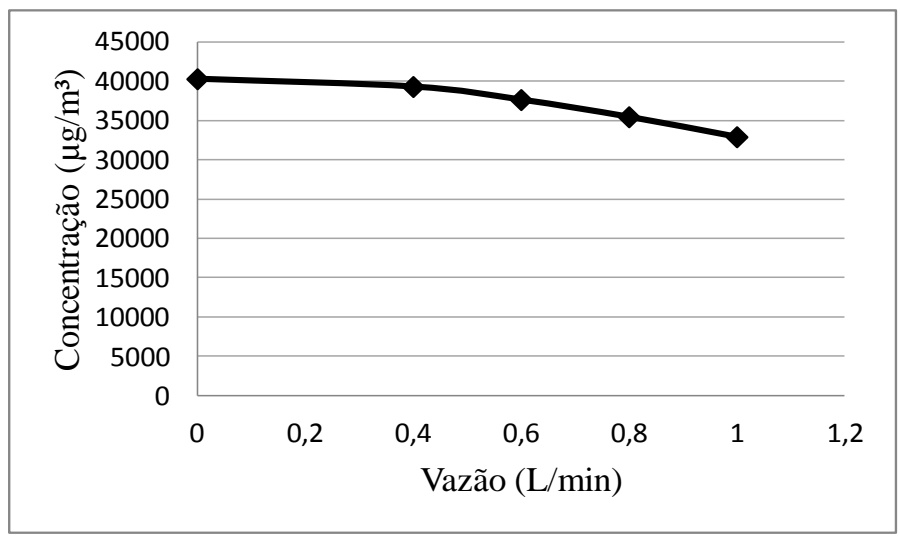

Figura 2 - Concentração de material particulado em $\mu \mathrm{g} / \mathrm{m}^{3}$ por vazão de líquido em $\mathrm{L} / \mathrm{min}$.

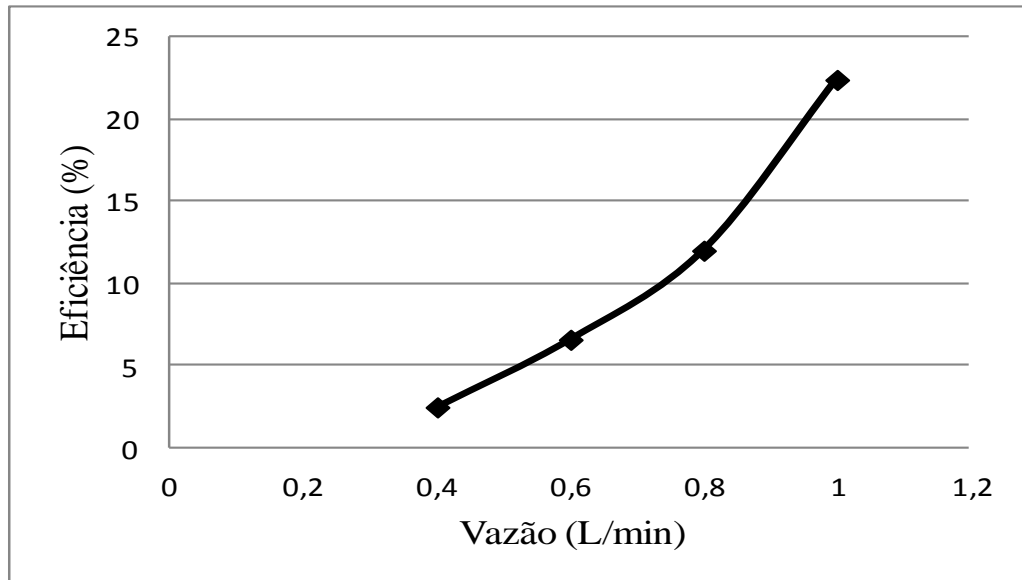

Figura 3 - Eficiência (\%) por vazão de líquido em L/min. 


\subsection{Remoção de gases contaminantes}

Os testes de amostragem de gases emitidos pela queima da biomassa coletados pelo Venturi foram realizados simultaneamente por ambos os analisadores Eurotron inseridos em pontos anterior e posterior ao lavador. Pode se observar a queda de concentração do poluente gasoso de acordo com o aumento da vazão. Nas Figuras 4, 5 e 6 são mostrados os dados das concentrações dos gases poluentes $\mathrm{CO}, \mathrm{CO}_{2}$ e $\mathrm{NO}_{\mathrm{X}}$, respectivamente. Pode-se observar que ocorreu a queda da concentração destes gases com o aumento da vazão de água no lavador.

Figura 4 a redução de concentração de $\mathrm{CO}$ a medida que se aumentava a vazão de líquido com destaque para a maior eficiência de $96,69 \%$ alcançada com a vazão de 0,6 L/min. Na figura 5 demonstrou-se a redução de $\mathrm{CO}_{2}$ com o aumento da vazão com o melhor resultado de $92,12 \%$ utilizando a vazão de $1 \mathrm{~L} / \mathrm{min}$. Analisando o material $\mathrm{NO}_{\mathrm{X}}$ na figura 6 obteve-se a melhor eficiência de $97,14 \%$ com a vazão de $0,8 \mathrm{~L} / \mathrm{min}$, todos os materiais tiveram alta eficiência na coleta superando os resultados obtidos por Poumohammadbagher et al. (2011), com uma vazão de $4 \mathrm{~L} / \mathrm{min}$ de água obtiveram a eficiência para $\mathrm{CO}_{2}$ e $\mathrm{NO}_{\mathrm{X}}$ de $35 \%$ e $58 \%$.

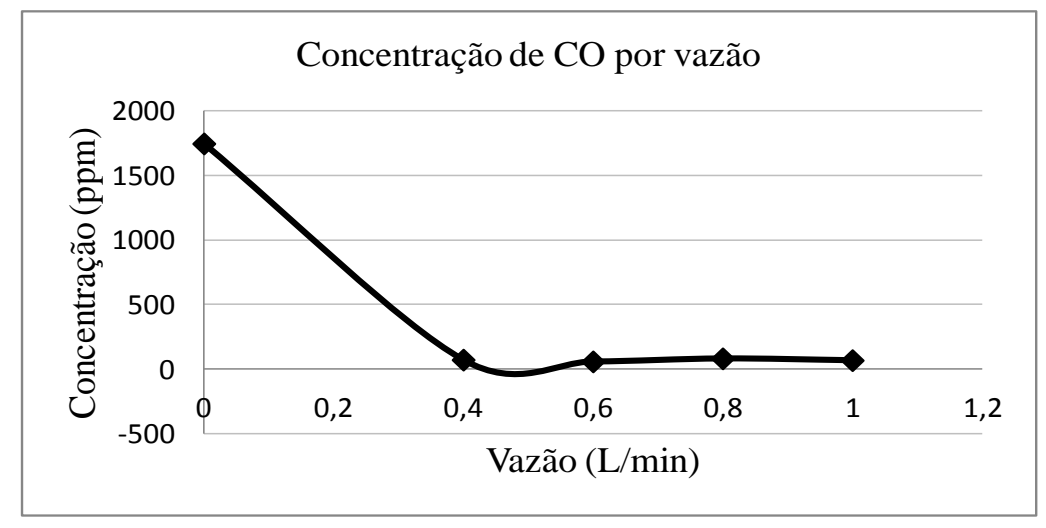

Figura 4 - Concentração em ppm de CO por vazão de líquido em L/min.

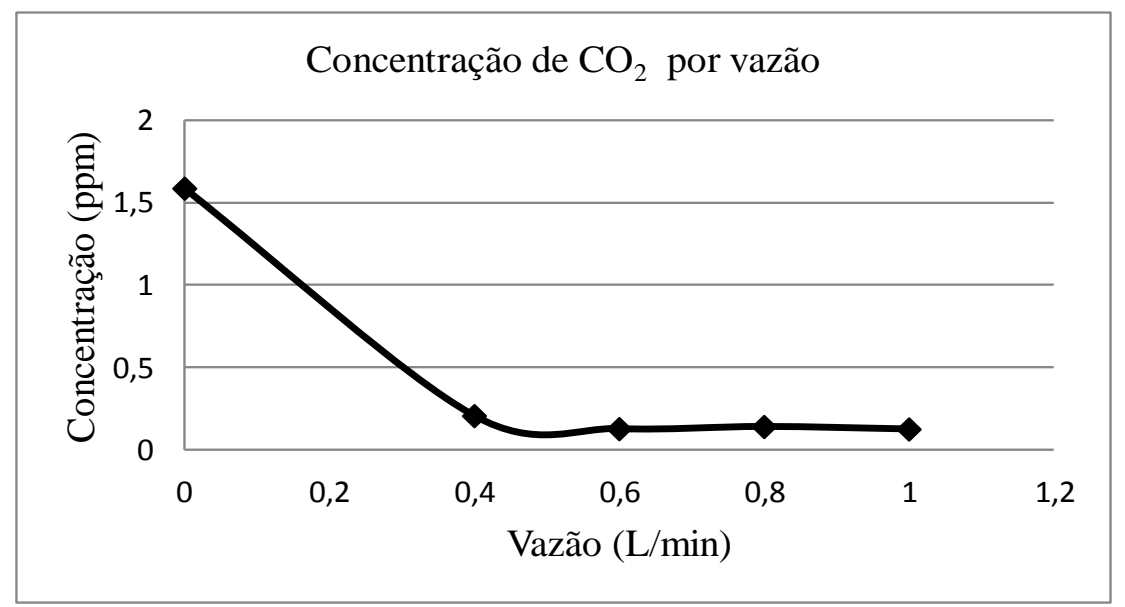

Figura 5 - Concentração em ppm de $\mathrm{CO}_{2}$ por vazão de líquido em L/min. 
O lavador Venturi utilizando água como líquido de lavagem mostrou-se eficiente na coleta de gases contribuintes do efeito estufa e emitidos pela queima de maravalha de pinus.

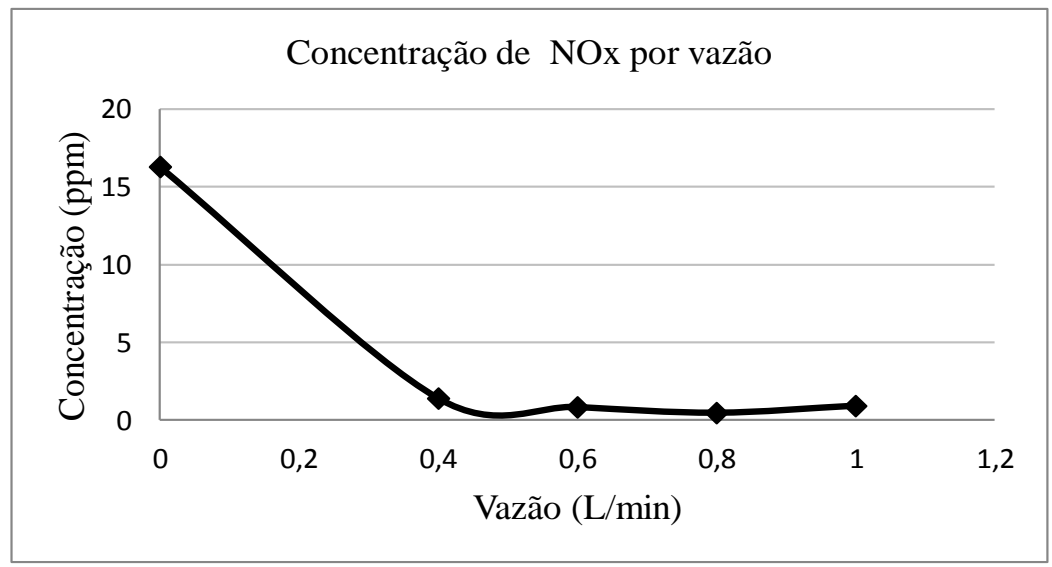

Figura 6 - Concentração em ppm de NOx por vazão de líquido em L/min.

$\mathrm{Na}$ figura 7 são apresentadas todas as eficiências obtidas no controle de $\mathrm{CO}, \mathrm{CO}_{2}$ e $\mathrm{NO}_{\mathrm{X}}$, utilizando as vazões citadas no trabalho.

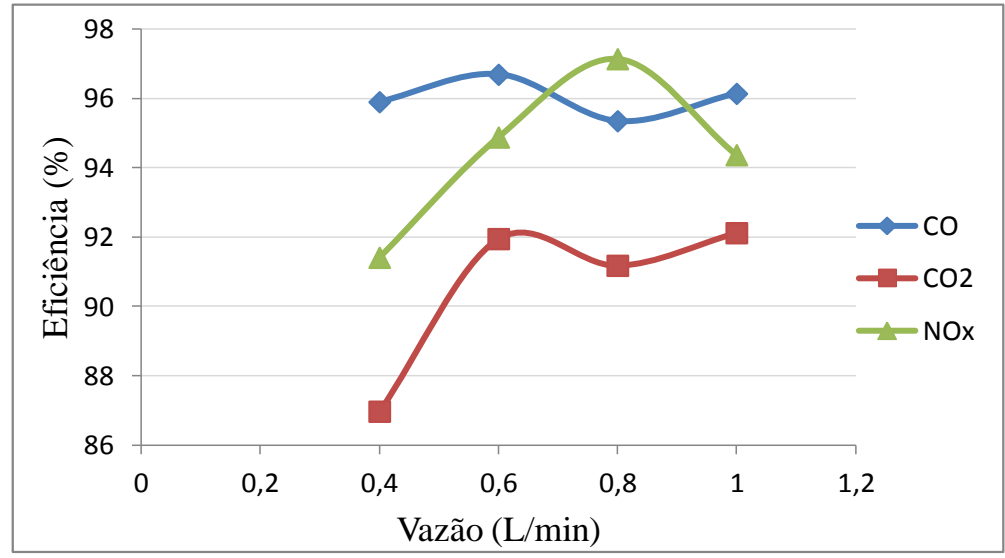

Figura 7 - Eficiência (\%) por vazão de líquido em L/min.

\section{CONCLUSÕES}

De acordo com os resultados obtidos, nas condições experimentais de utilização de maravalha de pinus como biomassa florestal pode-se concluir que:

- Contribuiu para o levantamento de dados da eficiência do lavador Venturi;

- Com o aumento da vazão na injeção de líquido ocorreu a diminuição de concentração do material particulado e a diminuição de emissão dos materiais gasosos; 
- Através dos resultados experimentais constatou-se significativamente a eficiência do lavador Venturi. Na emissão do material gasoso, obteve seu máximo de eficiência de $97,14 \%$ no controle de $\mathrm{NO}_{\mathrm{X}}$ com vazão de $0,8 \mathrm{~L} / \mathrm{min}$, superior a literatura que menciona uma eficiência de $90 \%$;

A escolha pelo lavador Venturi como equipamento de controle neste trabalho deve-se à sua utilização na coleta tanto para material particulado quanto para gases poluentes, o que não é observado para os demais equipamentos de controle existentes. Para a implantação do Venturi deve-se considerar seu custo e benefício que irá proporcionar na diminuição da emissão de gases tóxicos na queima de biomassa florestal, deve se levar em conta também a restrição do espaço, como o conjunto de equipamentos, utilização de certos tipos de poeira, diâmetro de partículas a ser coletadas e custo do lavador.

\section{AGRADECIMENTOS}

À PROEX - Pró-Reitoria de Extensão Universitária - Universidade Estadual Paulista "Júlio de Mesquita Filho" - UNESP - através de auxílios financeiros para participação em eventos científicos.

À FAPESP - Fundação de Amparo à Pesquisa do Estado de São Paulo - pela bolsa concedida (processo 2013/03892-0) e pelo financiamento dos equipamentos utilizados nesta pesquisa (processo 08/04490-4).

À Universidade Estadual Paulista “Júlio de Mesquita Filho" - UNESP, Campus de Itapeva, pelo apoio institucional.

\section{REFERÊNCIAS}

AMARAL, S. S. Monitoramento de poluentes emitidos pela queima de biomassa florestal. 2013. 171 f. Tese (Mestrado) - Faculdade de Engenharia do Campus de Guaratinguetá, Universidade Estadual Paulista, UNESP, Itapeva, 2013.

CETESB. Material particulado. Disponível em:<http://www.cetesb.sp.gov.br/ar/InformaesBsicas/21-Poluentes.mp>.

COSTA, M. A. M. et al. Real-time sampling of particulate matter smaller than $2.5 \mu \mathrm{m}$ from Amazon forest biomass combustion. Atmospheric Environment, v. 54, p.480-489, 2012.

MÜLlER, F. B. Biomassa Energias Renováveis: atualizado em 2008. Disponível em: <http://www.mma.gov.br/clima/energia/energias-renovaveis/biomassa>. Acesso em: mar. 2014.

POURMOHAMMADBAGHER, A. et al. Simultaneous removal of gaseous pollutants with a novel swirl wet scrubber. Chemical Engineering and Processing: Process Intensification, v. 50, p. 773-779, 2011.

RICCO JUNIOR, E. Materiais Filtrantes: publicado em 2007. Disponível em: < http://meiofiltrante.com.br/materias.asp?action=detalhe\&id=285 >. Acesso em: fev. 2014. 